OPEN ACCESS

Edited by: Zvi Fridlender,

Hadassah Medical Center, Israel

Reviewed by:

Gregory B. Lesinski,

Emory University, United States Limin Zheng,

Sun Yat-sen University, China

*Correspondence:

Scott I. Abrams

scott.abrams@roswellpark.org

Specialty section:

This article was submitted to Cancer Immunity and Immunotherapy,

a section of the journal

Frontiers in Immunology

Received: 29 May 2020

Accepted: 21 July 2020

Published: 27 August 2020

Citation:

Kramer ED and Abrams SI (2020)

Granulocytic Myeloid-Derived

Suppressor Cells as Negative

Regulators of Anticancer Immunity.

Front. Immunol. 11:1963.

doi: 10.3389/fimmu.2020.01963

\section{Granulocytic Myeloid-Derived Suppressor Cells as Negative Regulators of Anticancer Immunity}

\author{
Elliot D. Kramer and Scott I. Abrams* \\ Department of Immunology, Roswell Park Comprehensive Cancer Center, Buffalo, NY, United States
}

The immune system plays a critical role in cancer progression and response to therapy. However, the immune system can be compromised during the neoplastic process. Notably, the myeloid lineage, which gives rise to granulocytic cells, including neutrophils, is a well-recognized target of tumor-mediated immune suppression. Ordinarily, granulocytic cells are integral for host defense, but in neoplasia the normal process of granulocyte differentiation (i.e., granulopoiesis) can be impaired leading instead to the formation of granulocytic (or PMN)-myeloid-derived suppressor cells (MDSCs). Such cells comprise various stages of myeloid differentiation and are defined functionally by their highly pro-tumorigenic and immune suppressive activities. Thus, considerable interest has been devoted to impeding the negative contributions of PMN-MDSCs to the antitumor response. Understanding their biology has the potential to unveil novel therapeutic opportunities to hamper PMN-MDSC production in the bone marrow, their mobilization, or their effector functions within the tumor microenvironment and, therefore, bolster anticancer therapies that require a competent myeloid compartment. In this review, we will highlight mechanisms by which the neoplastic process skews granulopoiesis to produce PMN-MDSCs, summarize mechanisms by which they execute their pro-tumorigenic activities and, lastly, underscore strategies to obstruct their role as negative regulators of antitumor immunity.

Keywords: polymorphonuclear myeloid-derived suppressor cells, antitumor immunity, immune suppression, immunotherapy, tumor progression

\section{INTRODUCTION}

Myeloid-derived suppressor cells (MDSCs) are cells of the immune system that are widely described as an immature subset arising from the myeloid lineage and defined by their ability to impede both innate and adaptive immunity, including against cancer (1-4). The suppressive activity of MDSCs has been demonstrated both in vitro and in vivo to inhibit the activation and expansion of adaptive $\mathrm{T}$ cell immunity, as well as to promote the growth and spread of cancer (5). Natural killer (NK) cells of the innate immune system are also susceptible to MDSC-mediated immune suppression through exposure to nitric oxide (NO) and TGF- $\beta(6,7)$. Broadly, in mouse models, MDSCs are divided into two main subsets: monocytic (M-MDSCs) and polymorphonuclear (PMN-MDSCs, also known as granulocytic MDSCs). M-MDSCs resemble monocytes and are phenotypically defined as $\mathrm{CD} 11 \mathrm{~b}^{+} \mathrm{Ly} 6 \mathrm{C}^{\mathrm{hi}} \mathrm{Ly} 6 \mathrm{G}^{-}$. PMN-MDSCs resemble 
neutrophils and are defined as $\mathrm{CD}_{11 \mathrm{~b}}{ }^{+} \mathrm{Ly}_{6 \mathrm{C}}{ }^{\mathrm{lo}} \mathrm{Ly}_{6 \mathrm{G}}{ }^{+}$ (8). In humans, at least three distinct subsets have been identified, reflecting those of granulocytic $\left(\mathrm{CD} 11 \mathrm{~b}^{+} \mathrm{CD}_{3}{ }^{+} \mathrm{CD} 15^{+} \mathrm{CD} 14^{-} \mathrm{HLA}_{-} \mathrm{DR}^{-}\right)$or monocytic $\left(\mathrm{CD}_{11 b^{+}} \mathrm{CD} 3^{+} \mathrm{CD}^{-} 5^{-} \mathrm{CD} 14^{+} \mathrm{HLA}_{-\mathrm{DR}}{ }^{\mathrm{lo} /-}\right)$ origin, as well as a more immature state lacking expression of both granulocytic and monocytic markers (9).

In cancer, MDSCs are abundant both in the tumor microenvironment (TME) and the periphery, such as the spleen and blood. Interestingly, few if any MDSCs are found in lymph nodes. The abundance of MDSCs, and the PMN-MDSC subset in particular, in cancer patients has been demonstrated to directly correlate with a poorer prognosis, resistance to diverse therapies, and reduced overall survival in multiple solid tumor types (10-17). PMN-MDSCs drive tumor growth and progression by suppressing $\mathrm{T}$ cell activation, as well as enhancing tumor invasion and metastasis. PMN-MDSCs can directly inhibit the activity of $\mathrm{CD}^{+}$cytotoxic T lymphocytes (CTLs). Mechanisms of CD8 ${ }^{+}$ CTL inhibition include: (1) expression of the immune checkpoint ligand, programmed death-ligand 1 (PD-L1); (2) mobilization of regulatory $\mathrm{T}$ cells; and (3) release of immunosuppressive mediators or signals such as interleukin-10 (IL-10), arginase1 (Arg-1), and reactive oxygen species (ROS) $(6,18,19)$. The release of such mediators within the TME fosters a chronic inflammatory response that promotes tumor growth akin to "an un-healing wound."

PMN-MDSCs are also capable of inducing tumor progression independently of their impact on the immune system. Specifically, they facilitate tumor angiogenesis by the release of pro-angiogenic factors (20) and promote the epithelial-tomesenchymal (EMT) transition, both critical steps in metastatic progression (21). Furthermore, PMN-MDSCs assist in degrading the extracellular matrix by releasing metalloproteases, such as MMP9, which supports the pre-metastatic niche (22). While both MDSC subsets are important in tumor progression, this article will focus on the PMN-MDSC subset reflecting the theme of this review series.

\section{TUMOR-DRIVEN DISRUPTION OF GRANULOPOIESIS}

Ordinarily, granulocytic populations develop in the bone marrow and have a high turnover rate once they are released into the circulation and, thus, must be replenished continuously through the process of granulopoiesis (23). As with all circulating immune cells, the ultimate precursor of granulocytic cells is the hematopoietic stem cell (HSC). In the process of granulopoiesis, the HSC mesenchymal progenitor population differentiates into common myeloid progenitors (CMPs) followed by differentiation into granulocyte-monocyte progenitor (GMPs). As its name suggests, the GMP further bifurcates into monocytic progenitors (MPs) or granulocytic progenitors (GP), the immediate antecedents to monocytes or granulocytes, respectively (24).

However, in cancer, granulopoiesis is compromised, leading instead to the accumulation of PMN-MDSCs $(25,26)$.
Each developmental junction in granulopoiesis is tightly choreographed by the differential expression of myelopoietic growth factors (e.g., G-CSF, M-CSF, or GM-CSF) and integral transcription factors. These "master regulators" are essential to the development and maturation of normal functional granulocytes, but in the face of tumor burden and the type and concentration of factors that tumors produce, these networks become dysregulated and impair myeloid differentiation driving the accumulation of PMN-MDSCs (27). Therefore, understanding the transcription factors that underlie MDSC development and function is crucial to improving the response of patients to immune-based therapies that require a competent myeloid compartment (28). In this review, we will highlight the important roles of several transcription factors known to drive PMN-MDSC production or function (Figure 1), including: interferon regulatory factor-8 (IRF8), signal transducer and activator of transcription (STAT) 3 or 5, CCAAT/enhancebinding protein- $\beta(\mathrm{C} / \mathrm{EBP} \beta)$, and $\beta$-catenin as well as their regulatory signals. While several transcription pathways are illustrated, the extent of crosstalk among them remains to be fully understood. We will then present future directions that exploit this knowledge toward the development of novel approaches to mitigate PMN-MDSC burden and improve antitumor responses.

\section{TRANSCRIPTIONAL REGULATORS OF PMN-MDSCs}

\section{Interferon Regulatory Factor-8}

Interferon regulatory factor-8 (IRF8) is a $48-\mathrm{kD}$ protein containing two distinct $\mathrm{N}$-terminal and $\mathrm{C}$-terminal domains. The N-terminal domain contains the DNA binding site of the transcription factor, while the C-terminal domain contains the IRF association site (29). This IRF8 association domain (IAD) enables IRF8 to interact with other IRF family proteins, such as IRF1, IRF2, AP-1, or PU.1 (30). The heterodimerization of IRF8 with other binding partners determines the specific DNA binding motif recognized within the promoter regions of target genes and whether the binding of the particular IRF8 heterodimer to that region activates or represses target gene transcription (31).

IRF8 is expressed strongly by B cells and activated T cells of the lymphoid lineage and monocytes, macrophages, and dendritic cells (DCs) of the myeloid lineage (32-34). Indeed, IRF8 expression is essential for normal myelopoiesis in which it guides the differentiation of monocytic vs. granulocytic lineages at the GMP stage (35). At this stage, IRF8 acts as a positive regulator of monocytic and DC differentiation and as a negative regulator of granulocytic differentiation especially neutrophils $(36,37)$ This bifurcation point of the myeloid lineage is driven by the steady increase in the expression of IRF8 in MPs, and the reduction in the expression of IRF8 in GPs and eventually neutrophils. Indeed, in the global IRF8-deficient $\left(\mathrm{IRF}^{-/-}\right.$) model, mice exhibit profound alterations in hematopoiesis, with a marked skewing of myelopoiesis toward neutrophil production (38).

These neutrophils harbor an immature myeloid phenotype and, interestingly, have been shown to inhibit $\mathrm{T}$ cell activation; 


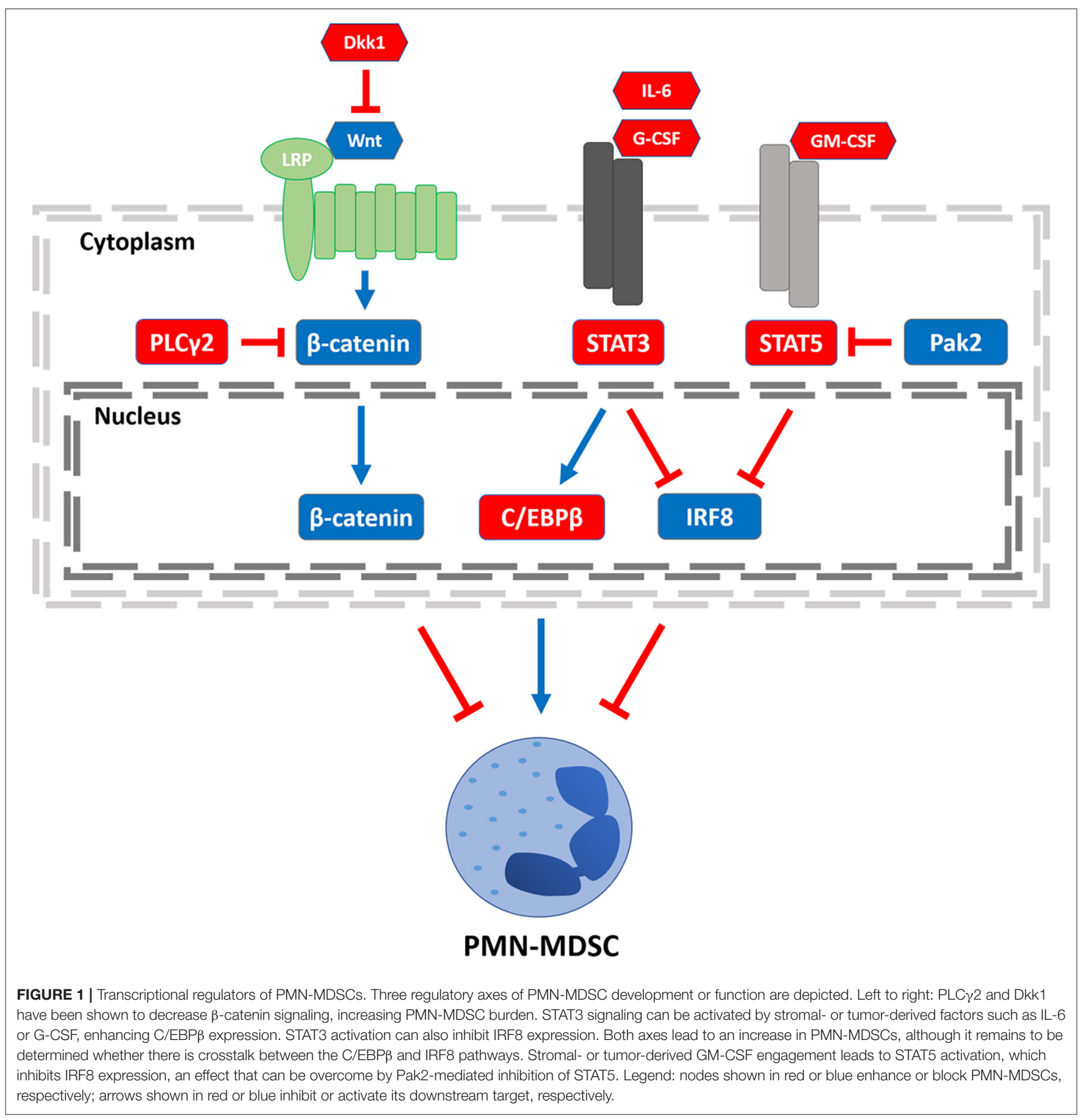

therefore, these IRF8-deficient myeloid cells seemed to mirror tumor-induced PMN-MDSCs at multiple levels (39). Furthermore, differential gene expression analyses revealed that IRF8-deficient myeloid cells displayed a gene expression profile that resembled tumor-induced PMN-MDSCs significantly more so compared to those of the non-tumor-bearing controls (39). Despite an increase in the total number of myeloid cells, the neutrophil bias comes at the expense of the $\mathrm{Ly} \mathrm{C}^{+}$ monocytic, $\mathrm{CD}^{+}$and $\mathrm{CD}^{+} 03^{+}$DC lineages. These shifts highlight the essential roles of IRF8 in moderating normal myelopoiesis and the generation of functional monocytic, DC, and granulocytic populations.

Previous work in our laboratory has demonstrated that IRF8 expression is reduced in both MDSC subsets and their progenitors in mouse models of mammary carcinoma $(39,40)$. These findings have been recapitulated by other investigators examining a number of solid tumors and hematologic malignancies (41-43). Tumor-driven downregulation of 
IRF8 was found to dysregulate myelopoiesis at least in part by promoting the expansion of tumor-derived GPs, which selectively led to PMN-MDSCs. Importantly, these tumorderived GPs were shown to mirror the transcriptional profile of GPs isolated from IRF8 ${ }^{-/-}$mice compared to those of the non-tumor-bearing controls, lending further evidence that the loss of IRF8 expression during granulopoieses skews myeloid differentiation toward PMN-MDSCs. In a reciprocal manner, Netherby et al. (40) found that enforcing overexpression of IRF8 mitigated the expansion of GPs in these same mammary tumor models. On a functional level, Waight et al. (39) demonstrated that enhancing IRF8 expression in the myeloid compartment using a tissue-specific (CD11b) IRF8-transgenic mouse model led to a decrease in the abundance of PMN-MDSCs and a significant improvement in the antitumor response to anti-CTLA-4 immune checkpoint inhibitor therapy. Furthermore, a negative correlation between the expression of IRF8 and the abundance of the immature $\mathrm{CD}_{3}{ }^{+} \mathrm{HLA}^{-} \mathrm{DR}^{-}$MDSC subset in breast cancer patients substantiated the important role of IRF8 as a negative regulator of PMN-MDSC levels originally observed in mouse tumor models.

\section{STAT3, STAT5, and C/EBP $\beta$}

Two negative regulators of IRF8 expression are the STAT3 and STAT5 proteins belonging to the highly conserved STAT family of transcription factors, which have been well-described as mediators of cellular immunity, differentiation, and cell cycle regulation (44). The STAT family is characterized by four unique domains: the Src homology 2 (SH2), C-terminal transactivation, coiled-coil, and DNA-binding regions that mediate their activation, dimerization, nuclear translocation, and DNA-binding, respectively. Canonically, STAT3 and STAT5 are activated by a cytokine receptor-associated Janus kinase (JAK), which leads to the phosphorylation of the STAT3 or STAT5 transactivation domain and subsequent dimerization and translocation to the nucleus $(45,46)$. Work in our laboratory identified STAT3 activation downstream of the GCSF receptor (G-CSFR), as a previously unrecognized negative regulator of IRF8 expression and a driver of PMN-MDSC accumulation (39). STAT3 signaling has also been observed by other groups to promote PMN-MDSC function by enhancing Arg-1 expression (47). Inhibiting STAT3 signaling abrogated the function and development of the $\mathrm{CD} 33^{+} \mathrm{CD} 11 \mathrm{~b}^{+} \mathrm{CD} 15^{+}$ PMN-MDSCs (48).

Inhibition of STAT3 using the multitargeted tyrosine kinase inhibitor (TKI) Sunitinib has been shown to decrease MDSC burden in mouse renal cell carcinoma models (49). In addition to Sunitinib, Dasatinib, a broader spectrum TKI, has been shown to target and reduce M-MDSCs in CML patients. In other cancer models, however, while Dasatinib was able to modulate MDSCs, it strongly negatively impaired $\mathrm{T}$ cell activity which outweighed its potential use for immunotherapy (50-52). Promotion of angiogenesis via the release of vascular endothelial growth factor (VEGF) is one mechanism by which MDSCs exert their protumorigenic effects in the TME. For example, in head and neck squamous cell carcinoma (HNSCC), inhibiting STAT3 was shown to decrease the production of VEGF by MDSCs, although the study did not delineate between monocytic and PMN subsets (47). Furthermore, active phosphorylated STAT3 is highly expressed in the human $\mathrm{CD}_{3}{ }^{+} \mathrm{HLA}^{-D R^{-}}$MDSC subset from the peripheral blood of metastatic melanoma patients when compared to healthy donors $(26,53)$. Addition of the STAT3 inhibitor AG490 alone was sufficient to significantly reduce MDSC-mediated $\mathrm{T}$ cell suppression and pro-angiogenic cytokine production in murine and human xenograft HNSCC models, respectively (54). In the study by Vasquez-Dundell (47) noted above, STAT3 inhibition using the novel compound Stattic decreased MDSC suppressive function by abrogating Arg-1 expression in MDSCs from patients with HNSCC. We established that at least one mechanism by which STAT3 facilitates PMN-MDSC expansion in cancer models is IRF8dependent by demonstrating a unique G-CSF-STAT3-IRF8 axis (39). Thus, STAT3 is an important driver of the PMN-MDSC response by regulating both immunosuppressive and proangiogenic factors, as well as their development by inhibiting the expression IRF8.

In addition to its effects on IRF8 regulation, STAT3 activation has been shown to impact additional transcription factors important in PMN-MDSC biology; e.g., C/EBPs (55). $\mathrm{C} / \mathrm{EBPs}$ are a family of transcription factors important in various cell functions, including metabolism, differentiation, and proliferation $(56,57)$. However, $\mathrm{C} / \mathrm{EBP} \beta$ in particular has been implicated as a key transcriptional regulator of emergency granulopoiesis (58). In a mouse sepsis model, PMN-MDSC numbers were significantly diminished in both early and late disease using a myeloid-specific $L y s M$-cre conditional knockout of $\mathrm{C} / \mathrm{EBP} \beta$ (59). In the context of cancer, Tek-cre conditional knockout of $\mathrm{C} / \mathrm{EBP} \beta$ significantly decreased the abundance

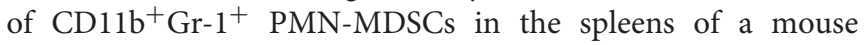
model of sarcoma (60). Furthermore, deletion of C/EBP $\beta$ in this study led to a decrease in the expression of the immunosuppressive factors Nos2, which encodes for inducible nitric oxide synthase (iNOS), and Arg-1. Interestingly, long non-coding $\mathrm{C} / \mathrm{EBP} \beta$ RNA (lnc- $\mathrm{C} / \mathrm{EBP} \beta$ ), which inhibits $\mathrm{C} / \mathrm{EBP} \beta$ transcriptional activity by binding to the LIP isoform, has been shown to preferentially promote PMN-MDSC expansion (61, 62). A STAT3-C/EBP $\beta$ axis has been shown to impact PMNMDSC biology in inflammation and cancer, but the role of noncoding RNAs and whether this axis interfaces with IRF8 requires further examination.

The STAT5 transcription factor is reported to be downstream of GM-CSF receptor engagement (63). GM-CSF is an important signaling molecule described to mediate the maturation and function of myeloid cells, including neutrophils (64). Recent work by Zeng et al. (65) uncovered a key role for the p21activated kinase 2 (Pak2) in mediating the production of PMN-MDSCs. Their work elucidated a myeloid skewing of hematopoiesis in the $M x 1$-cre-driven Pak2 conditional knockout model. In this knockout model, a significant increase in granulocytes in vivo was observed. Further work (66) determined that these granulocytic cells were indeed PMN-MDSCs based on their $\mathrm{T}$ cell suppressive behavior, and that the overall number and suppressive function of PMN-MDSCs from the conditional Pak2 knockout host was greater than that of the wild-type controls. 
Importantly, they identified that Pak2-deficiency sensitized myeloid progenitors to GM-CSF stimulation, which led to the accumulation of PMN-MDSCs. This GM-CSF sensitivity was shown to increase the activity of STAT5 and decrease IRF8 expression, in agreement with the work of our laboratory (39). Therefore, enhancing Pak2 activity in myeloid progenitors may serve as a therapeutic target for future strategies aimed at increasing IRF8 expression and decreasing PMN-MDSC accumulation in cancer.

\section{$\beta$-catenin}

$\beta$-catenin protein is a widely expressed and highly conserved protein characterized by its importance as a transcription factor that regulates cellular differentiation and proliferation. $\beta$-catenin is readily expressed in self-renewing tissues such as the epithelium of the gut, base of the hair follicle, the bone matrix, and hematopoietic bone marrow, but its activity is tightly controlled by the $\beta$-catenin degradation complex (67). This complex is an assembly of proteins that facilitate the phosphorylation and then ubiquitination and degradation of $\beta$ catenin. Canonical $\beta$-catenin signaling is activated after Wnt family ligands bind to the Frizzled receptor. This, in turn, leads to the phosphorylation of the $\beta$-catenin inhibitory complex and its subsequent degradation. Destruction of the inhibitory complex then stabilizes $\beta$-catenin in the cytosol. Free of negative regulation, $\beta$-catenin can then translocate to the nucleus and associate with transcriptional co-factors to drive the expression or repression of target genes (67). Constitutive activation of $\beta$-catenin signaling due to genetic mutations has been shown to induce neoplastic growth in cancers such as colorectal adenocarcinoma (68). $\beta$-catenin signaling also plays an important role in the normal differentiation of myeloid progenitors $(69,70)$.

Dysregulation of $\beta$-catenin signaling in myeloid cells has been implicated in promoting PMN-MDSC expansion in cancer (71). Capietto et al. (72) demonstrated that phospholipase C $\gamma 2$ (PLC $\gamma 2$ ) drives $\beta$-catenin expression in PMN-MDSCs and that together, this PLC $\gamma 2-\beta$-catenin axis inhibits the accumulation and suppressive phenotype of PMN-MDSCs in mouse models of lung carcinoma and melanoma. This same group went on to identify Dickkopf-related protein 1 (Dkk1), a circulating soluble inhibitor of $\beta$-catenin activity, as a key source of $\beta$-catenin downregulation in their mouse tumor models (73). They extended these findings to cancer patients by correlating increased Dkk1 expression with an increase in PMN-MDSC abundance in pancreatic carcinoma samples. Furthermore, depletion of Dkk1 using an anti-Dkk1 antibody was sufficient to decrease tumor burden in their mouse tumor models; importantly, there was no additional significant impact on tumor growth following anti-Gr-1 antibody treatment suggesting that $\beta$-catenin mediated its effects through PMN-MDSCs.

The role of $\beta$-catenin in PMN-MDSC biology was further strengthened by Qian et al. (74) who showed that Cullin 4B (CUL4B), a scaffold protein known for its role in epigenetic repression of tumor suppressor genes, along with AKT and $\beta$ catenin negatively regulated PMN-MDSC numbers and function. Utilizing the Tek-cre conditional knockout system to selectively delete CUL4B in endothelial and hematopoietic cells, their work further demonstrated that the conditional deletion of CUL4B in these cells decreased $\beta$-catenin activity in PMN-MDSCs. This decrease in $\beta$-catenin led to an increase in PMN-MDSC accumulation and immune suppressive activity. As with the $\mathrm{C} / \mathrm{EBP} \beta$ pathway, it remains to be determined whether there is crosstalk between the $\beta$-catenin and IRF8 pathways. Additionally, $\beta$-catenin signaling is important in maintaining $\mathrm{CD}^{+} \mathrm{T}$ cell stemness and central memory responses, as well as enabling $\mathrm{T}$ cell tumor infiltration $(75,76)$. Thus, $\beta$-catenin signaling in the immune system likely plays important roles in multiple capacities - on the one hand, acting as a negative regulator of PMN-MDSCs and, on the other hand, acting as a positive regulator of $\mathrm{T}$ cell functionality. Understanding the $\beta$-catenin pathway in PMNMDSC, as well as $\mathrm{T}$ cell biology may reveal novel therapeutic targets to enhance the efficacy of anti-cancer therapies.

\section{ANTI-MDSC-TARGETED THERAPIES IN HUMAN CANCERS}

While depleting or inactivating mouse PMN-MDSCs in vivo has been effective and has enhanced antitumor activity, particularly in combination regimens, therapies aimed at targeting human PMN-MDSCs in vivo have yet to similarly improve overall survival in patients (77). The prospect of combining PMN-MDSC-depleting or -inactivating strategies with other immune stimulatory agents, such as tumor vaccines or immune checkpoint inhibitors (ICIs), are a potentially effective way to concurrently mitigate PMN-MDSC involvement and heighten the efficacy of the antitumor immune response. The following is a brief summary of current anti-MDSC therapies that target and interfere with MDSC responses through different strategies.

\section{Cell Depletion}

Currently, there are two active clinical trials (NCT01803152), and (NCT02544880), which involve gemcitabine and tadalafil to deplete MDSC populations, respectively (Table 1). Gemcitabine is a chemotherapeutic agent known to inhibit DNA synthesis and, thus, the expansion of dividing cells (91). Interestingly, gemcitabine has been observed to also diminish MDSC abundance in both mouse models and patients, although the precise mechanism of action is not entirely clear $(78,92$, 93). Tadalafil is known to inhibit phosphodiesterase- 5 which, interestingly, target PMN-MDSC effector mechanisms, iNOS and Arg-1 expression $(79,80)$. In addition to the gemcitabine studies, the novel small molecule RGX-104 that targets the liver-X receptor is being tested in combination with existing ICIs or chemotherapeutics (NCT02922764). This agent has been shown to deplete MDSCs by apoptosis in non-small cell lung cancer $(81,82)$. The tri-specific anti-CD16/IL-15/CD33 fusion protein GTB-3550 is being explored as a potential intervention for MDSC depletion by antibody-dependent cellular cytotoxicity (NCT03214666) (83). 
TABLE 1 | Clinical Trials Therapeutically Targeting MDSCs.

\begin{tabular}{|c|c|c|c|}
\hline Mechanism & Trial Title & Intervention(s) & $\begin{array}{l}\text { Trial } \\
\text { No./reference }\end{array}$ \\
\hline Depletion & $\begin{array}{l}\text { Dendritic cell vaccine with or without gemcitabine pre-treatment for adults } \\
\text { and children with sarcoma }\end{array}$ & $\begin{array}{l}\text { Dendritic cell vaccine, lysate of tumor, } \\
\text { gemcitabine, imiquimod }\end{array}$ & $\begin{array}{l}\text { NCT01803152 } \\
(78)\end{array}$ \\
\hline Depletion & $\begin{array}{l}\text { PDE5 inhibition via tadalafil to enhance anti-tumor mucin } 1 \text { (MUC1) vaccine } \\
\text { efficacy in patients with HNSCC }\end{array}$ & Tadalafil, anti-MUC1 vaccine & $\begin{array}{l}\text { NCT02544880 } \\
(79,80)\end{array}$ \\
\hline Depletion & $\begin{array}{l}\text { A Study of RGX-104 in patients with advanced solid malignancies and } \\
\text { lymphoma }\end{array}$ & $\begin{array}{l}\text { RGX-104, nivolumab, ipilimumab, docetaxel, } \\
\text { pembrolizumab, carboplatin, pemetrexed }\end{array}$ & $\begin{array}{l}\text { NCT02922764 } \\
(81,82)\end{array}$ \\
\hline Depletion & $\begin{array}{l}\text { GTB-3550 (CD16/IL-15/CD33) tri-specific killer engager (TriKETM) for high } \\
\text { risk heme malignancies }\end{array}$ & GTB-3550 TriKE & $\begin{array}{l}\text { NCT03214666 } \\
\text { (83) }\end{array}$ \\
\hline Signaling & Ibrutinib and nivolumab in treating participants with metastatic solid tumors & Ibrutinib, nivolumab & $\begin{array}{l}\text { NCT03525925 } \\
(84)\end{array}$ \\
\hline Signaling & Histamine receptor 2 antagonists as enhancers of anti-tumor immunity & Ranitidine & $\begin{array}{l}\text { NCT03145012 } \\
(85)\end{array}$ \\
\hline Signaling & Myeloid-derived suppressor cells (MDSCs) in OSCC patients & $\beta$-glucan & $\begin{array}{l}\text { NCT04387682 } \\
(86)\end{array}$ \\
\hline Signaling & $\begin{array}{l}\text { VX15/2503 in combination with ipilimumab or nivolumab in patients with } \\
\text { head and neck cancer }\end{array}$ & VX15/2503, nivolumab, ipilimumab & $\begin{array}{l}\text { NCT03690986 } \\
(87,88)\end{array}$ \\
\hline Maturation & $\begin{array}{l}\text { Ipilimumab and all-trans retinoic acid combination treatment of advanced } \\
\text { melanoma }\end{array}$ & VESANOID, ipilimumab & $\begin{array}{l}\text { NCT02403778 } \\
(89)\end{array}$ \\
\hline Maturation & $\begin{array}{l}\text { Pembrolizumab and all-trans retinoic acid combination treatment of } \\
\text { advanced melanoma }\end{array}$ & Pembrolizumab with all-trans retinoic acid & $\begin{array}{l}\text { NCT03200847 } \\
(89)\end{array}$ \\
\hline Transcription & $\begin{array}{l}\text { A study of MTL-CEBPA in combination with a PD-1 inhibitor in patients with } \\
\text { advanced solid tumors (TIMEPOINT) }\end{array}$ & MTL-CEBPA, pembrolizumab & $\begin{array}{l}\text { NCT04105335 } \\
(90)\end{array}$ \\
\hline
\end{tabular}

a Reference refers to the original publication(s) that supported the rationale for the indicated clinical trial.

\section{Modulating Signaling Pathways}

Overcoming $\mathrm{CD}^{+} \mathrm{CTL}$ unresponsiveness or exhaustion by blocking immune checkpoint receptor-ligand interactions has led to dramatic clinical outcomes in subpopulations of patients with various cancer types. However, not all patients respond or display durable antitumor effects; therefore, targeting PMNMDSCs may constitute a strategy to bolster the efficacy of ICIs. To test this notion, NCT03525925 investigates the impact of ibrutinib on PMN-MDSC function, which is thought to decrease Bruton's tyrosine kinase activation and subsequent indolamine 2,3-dioxygenase mRNA expression in PMN-MDSCs (84), a well-known mechanism of $\mathrm{T}$ cell suppression. Interestingly, NCT03145012 seeks to repurpose the widely prescribed histamine receptor 2 inhibitor, ranitidine, to decrease PMN-MDSC burden (85). As an innovative approach, the dietary supplement, $\beta$-glucan, has shown promise in depleting PMN-MDSCs in preclinical models and is being actively investigated in oral squamous cell carcinoma (OSCC) (NCT04387682) (86). Another recent research direction has been targeting the signaling molecule Semaphorin 4D, which has been associated with PMN-MDSC recruitment or function $(87,88)$. These findings have led to the design of a clinical trial involving an anti-Semaphorin 4D monoclonal antibody, VX15/2503, combined with ICIs (NCT03690986).

\section{Enforcing Maturation}

It is also reasonable to develop therapies that target PMN-MDSC precursors to potentially abrogate their generation or expansion prior to their mobilization to the TME. Therefore, while much attention has been drawn toward testing therapies that target PMN-MDSCs themselves or their effector mechanisms, there remains a larger gap in progress toward identifying effective approaches that target the process of PMN-MDSC production in the first place, perhaps, by altering transcriptional regulation. Studies have made use of existing anti-leukemic agents, such as all-trans-retinoic acid (ATRA) (NCT03200847 and NCT02403778), which has led to a reduction in MDSC numbers or their function; however, their clinical efficacy requires further investigation $(77,89,94,95)$. Yet, there is still a specific lack of targeted therapies that leverage knowledge of the differentially expressed transcriptional elements discussed in this review, which are needed to impact or redirect myeloid differentiation.

\section{Regulating Transcriptional Events}

While directly targeting and enhancing the activity of transcription factors is highly desirable, the ability to do so pharmacologically has yet to be clinically realized. At present, there is an active clinical trial (NCT04105335), which directly targets a transcriptional regulator of PMN-MDSCs. This trial seeks to utilize a small activating RNA oligonucleotide agent to upregulate $\mathrm{C} / \mathrm{EBP} \alpha$ to decrease MDSC burden (90). Perhaps, additional approaches that target upstream or downstream nodes of relevant signaling pathways may be feasible and considered as therapeutic targets. For example, therapies that inhibit STAT3 activation $(47,49)$ have the potential to both increase IRF8 expression and decrease C/EBP $\beta$ expression, thereby mitigating PMN-MDSC burden. There is also published 
rationale for an interaction between $\beta$-catenin signaling and IRF8 expression (96), which may be achieved through the use of anti-Dkk1 antibody. Additional investigations into combination therapy approaches that decrease both PMN-MDSC burden and impede immune checkpoints are also warranted. In summary, understanding the factors and molecular mechanisms that drive dysregulated myelopoiesis, and granulopoiesis specifically given the predominance of PMN-MDSCs in cancer, will likely lead to the discovery of new therapeutic targets to mitigate the pro-tumorigenic effects of PMN-MDSCs.

\section{CONCLUSIONS}

Polymorphonuclear leukocytes, namely neutrophils, are essential for mediating acute inflammation and defending against pathogenic insults. These terminally differentiated cells have a high rate of turnover and are, therefore, continuously replenished by granulopoiesis in the bone marrow. The chronic inflammatory nature of tumorigenesis can promote the aphysiologic release of cytokines, chemokines, and growth factors that compromise the otherwise tightly coordinated process of granulopoiesis likely through disruption of transcriptional regulation. This dysregulation of granulopoiesis then culminates in the production of PMN-MDSCs, which migrate via the bloodstream into the TME where they carry out their immune suppressive and pro-tumorigenic activities. Indeed, the abundance of PMN-MDSCs in neoplasia has been significantly

\section{REFERENCES}

1. Brandau S, Trellakis S, Bruderek K, Schmaltz D, Steller G, Elian M, et al. Myeloid-derived suppressor cells in the peripheral blood of cancer patients contain a subset of immature neutrophils with impaired migratory properties. J Leukocyte Biol. (2011) 89:311-7. doi: 10.1189/jlb.0310162

2. Diaz-Montero CM, Salem ML, Nishimura MI, Garrett-Mayer E, Cole DJ, Montero AJ. Increased circulating myeloid-derived suppressor cells correlate with clinical cancer stage, metastatic tumor burden, and doxorubicincyclophosphamide chemotherapy. Cancer Immunol Immunother. (2009) 58:49-59. doi: 10.1007/s00262-008-0523-4

3. Movahedi K, Guilliams M, Van den Bossche J, Van den Bergh R, Gysemans $\mathrm{C}$, Beschin A, et al. Identification of discrete tumor-induced myeloid-derived suppressor cell subpopulations with distinct T cell-suppressive activity. Blood. (2008) 111:4233-44. doi: 10.1182/blood-2007-07-099226

4. Sade-Feldman M, Kanterman J, Ish-Shalom E, Elnekave M, Horwitz E, Baniyash M. Tumor necrosis factor-alpha blocks differentiation and enhances suppressive activity of immature myeloid cells during chronic inflammation. Immunity. (2013) 38:541-54. doi: 10.1016/j.immuni.2013.02.007

5. Dugast AS, Haudebourg T, Coulon F, Heslan M, Haspot F, Poirier N, et al. Myeloid-derived suppressor cells accumulate in kidney allograft tolerance and specifically suppress effector T cell expansion. J Immunol. (2008) 180:7898906. doi: 10.4049/jimmunol.180.12.7898

6. Greene S, Robbins Y, Mydlarz WK, Huynh AP, Schmitt NC, Friedman J, et al. Inhibition of MDSC trafficking with SX-682, a CXCR1/2 inhibitor, enhances NK-cell immunotherapy in head and neck cancer models. Clin Cancer Res. (2020) 26:1420-31. doi: 10.1158/1078-0432.CCR-19-2625

7. Tumino N, Besi F, Di Pace AL, Mariotti FR, Merli P, Li Pira G, et al. PMN-MDSC are a new target to rescue graft-versus-leukemia activity of NK cells in haplo-HSC transplantation. Leukemia. (2020) 34:9327. doi: 10.1038/s41375-019-0585-7 correlated with poor prognosis and decreased efficacy of anti-oncologic therapies across diverse cancer types. Therefore, there is sound and compelling rationale for therapeutically targeting PMN-MDSCs in neoplastic disease. While several approaches have been developed and applied in clinical settings, there remains important opportunities to develop better and more effective PMN-MDSC-targeting therapies. An alternative or additional approach to abrogate the involvement of PMN-MDSCs may be attacking their production at their point-of-origin in the bone marrow. To achieve this goal, it is important to understand and build upon our current understanding of the transcriptional mechanisms that underlie PMN-MDSC generation from their progenitors. Exploiting this knowledge has the promise to unveil novel therapeutic options to improve cancer patient outcomes impacted by high PMN-MDSC burden.

\section{AUTHOR CONTRIBUTIONS}

EK and SA wrote and edited the manuscript.

\section{FUNDING}

This work was supported by the R01CA172105 grant from the National Cancer Institute/NIH (to SA), the Roswell Park Alliance Foundation (to SA), and NIH training grant T32CA085183 (to EK).
8. Youn JI, Nagaraj S, Collazo M, Gabrilovich DI. Subsets of myeloid-derived suppressor cells in tumor-bearing mice. J Immunol. (2008) 181:5791802. doi: 10.4049/jimmunol.181.8.5791

9. Bronte V, Brandau S, Chen SH, Colombo MP, Frey AB, Greten $\mathrm{TF}$, et al. Recommendations for myeloid-derived suppressor cell nomenclature and characterization standards. Nat Commun. (2016) 7:10. doi: $10.1038 /$ ncomms 12150

10. Chai EQ, Zhang L, Li CQ. LOX-1+PMN-MDSC enhances immune suppression which promotes glioblastoma multiforme progression. Cancer Manage Res. (2019) 11:7307-15. doi: 10.2147/CMAR.S210545

11. Clavijo PE, Moore EC, Chen JH, Davis RJ, Friedman J, Kim Y, et al. Resistance to CTLA-4 checkpoint inhibition reversed through selective elimination of granulocytic myeloid cells. Oncotarget. (2017) 8:5580420. doi: 10.18632/oncotarget.18437

12. Lang S, Bruderek K, Kaspar C, Hoing B, Kanaan O, Dominas $\mathrm{N}$, et al. Clinical relevance and suppressive capacity of human myeloid-derived suppressor cell subsets. Clin Cancer Res. (2018) 24:4834-44. doi: 10.1158/1078-0432.CCR-17-3726

13. Limagne E, Euvrard R, Thibaudin M, Rebe C, Derangere V, Chevriaux A, et al. Accumulation of MDSC and Th17 cells in patients with metastatic colorectal cancer predicts the efficacy of a FOLFOX-bevacizumab drug treatment regimen. Cancer Res. (2016) 76:5241-52. doi: 10.1158/0008-5472.CAN-15-3164

14. Sheng IY, Diaz-Montero CM, Rayman P, Wei W, Finke JH, Kim JS, et al. Blood myeloid-derived suppressor cells correlate with neutrophil-to-lymphocyte ratio and overall survival in metastatic urothelial carcinoma. Target Oncol. (2020) 15:211-20. doi: 10.1007/s11523-020-00707-z

15. $\mathrm{Wu} \mathrm{P}, \mathrm{Wu} \mathrm{D}, \mathrm{Ni} \mathrm{C}, \mathrm{Ye} \mathrm{J}$, Chen $\mathrm{W}, \mathrm{Hu}$, et al. gamma delta T17 cells promote the accumulation and expansion of myeloid-derived suppressor cells in human colorectal cancer. Immunity. (2014) 40:785800. doi: 10.1016/j.immuni.2014.03.013 
16. Yamauchi Y, Safi S, Blattner C, Rathinasamy A, Umansky L, Juenger S, et al. Circulating and tumor myeloid-derived suppressor cells in resectable non-small cell lung cancer. Am J Respir Crit Care Med. (2018) 198:77787. doi: 10.1164/rccm.201708-1707OC

17. Zhong LM, Liu ZG, Zhou X, Song SH, Weng GY, Wen Y, et al. Expansion of PMN-myeloid derived suppressor cells and their clinical relevance in patients with oral squamous cell carcinoma. Oral Oncol. (2019) 95:15763. doi: 10.1016/j.oraloncology.2019.06.004

18. Gey A, Tadie JM, Caumont-Prim A, Hauw-Berlemont C, Cynober L, Fagon JY, et al. Granulocytic myeloid-derived suppressor cells inversely correlate with plasma arginine and overall survival in critically ill patients. Clin Experi Immunol. (2015) 180:280-8. doi: 10.1111/cei.12567

19. Janols H, Bergenfelz C, Allaoui R, Larsson AM, Ryden L, Bjornsson S, et al. A high frequency of MDSCs in sepsis patients, with the granulocytic subtype dominating in gram-positive cases. J Leukocyte Biol. (2014) 96:68593. doi: 10.1189/jlb.5HI0214-074R

20. Binsfeld M, Muller J, Lamour V, De Veirman K, De Raeve H, Bellahcene A, et al. Granulocytic myeloid-derived suppressor cells promote angiogenesis in the context of multiple myeloma. Oncotarget. (2016) 7:37931-43. doi: 10.18632/oncotarget.9270

21. Ouzounova M, Lee E, Piranlioglu R, El Andaloussi A, Kolhe R, Demirci MF, et al. Monocytic and granulocytic myeloid derived suppressor cells differentially regulate spatiotemporal tumour plasticity during metastatic cascade. Nat Commun. (2017) 8:13. doi: 10.1038/ncomms14979

22. Yan HH, Pickup M, Pang YL, Gorska AE, Li ZY, Chytil A, et al. Gr- $1+\mathrm{CD} 11 \mathrm{~b}+$ myeloid cells tip the balance of immune protection to tumor promotion in the premetastatic lung. Cancer Res. (2010) 70:613949. doi: 10.1158/0008-5472.CAN-10-0706

23. Kolaczkowska E, Kubes P. Neutrophil recruitment and function in health and inflammation. Nat Rev Immunol. (2013) 13:159-75. doi: 10.1038/nri3399

24. Kondo M, Wagers AJ, Manz MG, Prohaska SS, Scherer DC, Beilhack GE, et al. Biology of hematopoietic stem cells and progenitors: Implications for clinical application. Ann Rev Immunol. (2003) 21:759-806. doi: 10.1146/annurev.immunol.21.120601.141007

25. Mackey JBG, Coffelt SB, Carlin LM. Neutrophil maturity in cancer. Front Immunol. (2019) 10:11. doi: 10.3389/fimmu.2019.01912

26. Poschke I, Mougiakakos D, Hansson J, Masucci GV, Kiessling R. Immature immunosuppressive CD14(+)HLA-DR-/low cells in melanoma patients are Stat3(hi) and overexpress CD80, CD83, and DC-Sign. Cancer Res. (2010) 70:4335-45. doi: 10.1158/0008-5472.CAN-09-3767

27. Millrud CR, Bergenfelz C, Leandersson K. On the origin of myeloid-derived suppressor cells. Oncotarget. (2017) 8:364965. doi: 10.18632/oncotarget.12278

28. Trikha P, Carson WE. Signaling pathways involved in MDSC regulation. Biochim Biophys Acta Rev Cancer. (2014) 1846:5565. doi: 10.1016/j.bbcan.2014.04.003

29. Tamura T, Kurotaki D, Koizumi S. Regulation of myelopoiesis by the transcription factor IRF8. Int J Hematol. (2015) 101:34251. doi: 10.1007/s12185-015-1761-9

30. Schonheit J, Kuhl C, Gebhardt ML, Klett FF, Riemke P, Scheller $\mathrm{M}$, et al. PU.1 level-directed chromatin structure remodeling at the Irf8 gene drives dendritic cell commitment. Cell Rep. (2013) 3:161728. doi: 10.1016/j.celrep.2013.04.007

31. Murphy TL, Tussiwand R, Murphy KM. Specificity through cooperation: BATF-IRF interactions control immune-regulatory networks. Nat Rev Immunol. (2013) 13:499-509. doi: 10.1038/nri3470

32. Paschall AV, Zhang RH, Qi CF, Bardhan K, Peng L, Lu GM, et al. IFN Regulatory factor 8 represses GM-CSF expression in $\mathrm{T}$ cells to affect myeloid cell lineage differentiation. J Immunol. (2015) 194:236979. doi: $10.4049 /$ jimmunol.1402412

33. Tsujimura $\mathrm{H}$, Nagamura-Inoue $\mathrm{T}$, Tamura $\mathrm{T}$, Ozato $\mathrm{K}$. IFN consensus sequence binding protein/IFN regulatory factor- 8 guides bone marrow progenitor cells toward the macrophage lineage. J Immunol. (2002) 169:12619. doi: 10.4049/jimmunol.169.3.1261

34. Tsujimura H, Tamura T, Gongora C, Aliberti J, Sousa CRE, Sher A, et al. ICSBP/IRF-8 retrovirus transduction rescues dendritic cell development in vitro. Blood. (2003) 101:961-9. doi: 10.1182/blood-2002-05-1327
35. Becker AM, Michael DG, Satpathy AT, Sciammas R, Singh H, Bhattacharya D. IRF-8 extinguishes neutrophil production and promotes dendritic cell lineage commitment in both myeloid and lymphoid mouse progenitors. Blood. (2012) 119:2003-12. doi: 10.1182/blood-2011-06-364976

36. Aliberti J, Schulz O, Pennington DJ, Tsujimura H, Sousa CRE, Ozato K, et al. Essential role for ICSBP in the in vivo development of murine CD8 alpha(+) dendritic cells. Blood. (2003) 101:305-10. doi: 10.1182/blood-2002-04-1088

37. Tamura $T$, Nagamura-Inoue $T$, Shmeltzer Z, Kuwata T, Ozato K. ICSBP directs bipotential myeloid progenitor cells to differentiate into mature macrophages. Immunity. (2000) 13:155-65. doi: 10.1016/S1074-7613(00) 00016-9

38. Holtschke T, Lohler J, Kanno Y, Fehr T, Giese N, Rosenbauer F, et al. Immunodeficiency and chronic myelogenous leukemia-like syndrome in mice with a targeted mutation of the ICSBP gene. Cell. (1996) 87:30717. doi: 10.1016/S0092-8674(00)81348-3

39. Waight JD, Netherby C, Hensen ML, Miller A, Hu Q, Liu S, et al. Myeloidderived suppressor cell development is regulated by a STAT/IRF-8 axis. J Clin Investig. (2013) 123:4464-78. doi: 10.1172/JCI68189

40. Netherby CS, Messmer MN, Burkard-Mandel L, Colligan S, Miller A, Gomez EC, et al. The granulocyte progenitor stage is a key target of IRF8-mediated regulation of myeloid-derived suppressor cell production. J Immunol. (2017) 198:4129-39. doi: 10.4049/jimmunol.1601722

41. Hu XL, Bardhan K, Paschall AV, Yang DF, Waller JL, Park MA, et al. Deregulation of apoptotic factors $\mathrm{Bcl}-\mathrm{xL}$ and bax confers apoptotic resistance to myeloid-derived suppressor cells and contributes to their persistence in cancer. J Biol Chem. (2013) 288:19103-15. doi: 10.1074/jbc.M112. 434530

42. Ibrahim ML, Klement JD, Lu CW, Redd PS, Xiao W, Yang DF, et al. Myeloidderived suppressor cells produce IL-10 to elicit DNMT3b-dependent IRF8 silencing to promote colitis-associated colon tumorigenesis. Cell Rep. (2018) 25:3036. doi: 10.1016/j.celrep.2018.11.050

43. Redd PS, Ibrahim ML, Klement JD, Sharman SK, Paschall AV, Yang D, et al. SETD1B activates iNOS expression in myeloid-derived suppressor cells. Cancer Res. (2017) 77:2834-43. doi: 10.1158/0008-5472.CAN-16-2238

44. Yu $\mathrm{H}$, Pardoll D, Jove R. STATs in cancer inflammation and immunity: a leading role for STAT3. Nat Rev Cancer. (2009) 9:798-809. doi: 10.1038/nrc2734

45. Loh CY, Arya A, Naema AF, Wong WF, Sethi G, Looi CY. Signal Transducer and activator of transcription (STATs) proteins in cancer and inflammation: functions and therapeutic implication. Front Oncol. (2019) 9:15. doi: 10.3389/fonc.2019.00048

46. Yu H, Jove R. The stats of cancer - New molecular targets come of age. Nat Rev Cancer. (2004) 4:97-105. doi: 10.1038/nrc1275

47. Vasquez-Dunddel D, Pan F, Zeng Q, Gorbounov M, Albesiano E, Fu J, et al. STAT3 regulates arginase-I in myeloid-derived suppressor cells from cancer patients. J Clin Investig. (2013) 123:1580-9. doi: 10.1172/JCI60083

48. Mace TA, Ameen Z, Collins A, Wojcik S, Mair M, Young GS, et al. Pancreatic cancer-associated stellate cells promote differentiation of myeloid-derived suppressor cells in a STAT3-dependent manner. Cancer Res. (2013) 73:300718. doi: $10.1158 / 0008-5472$.CAN-12-4601

49. Xin H, Zhang CY, Herrmann A, Du Y, Figlin R, Yu H. Sunitinib inhibition of Stat 3 induces renal cell carcinoma tumor cell apoptosis and reduces immunosuppressive cells. Cancer Res. (2009) 69:250613. doi: 10.1158/0008-5472.CAN-08-4323

50. Giallongo C, Parrinello NL, La Cava P, Camiolo G, Romano A, Scalia M, et al. Monocytic myeloid-derived suppressor cells as prognostic factor in chronic myeloid leukaemia patients treated with dasatinib. J Cell Mol Med. (2018) 22:1070-80. doi: $10.1111 / \mathrm{jcmm} .13326$

51. Giallongo C, Parrinello NL, Tibullo D, La Cava P, Romano A, Chiarenza A, et al. Monocytic myeloid derived suppressor cells (M-MDSC) as prognostic factor in chronic myeloid leukemia patients treated with dasatinib. Blood. (2015) 126:3. doi: 10.1182/blood.V126.23.2767.2767

52. Lu X, Horner JW, Paul E, Shang XY, Troncoso P, Deng PN, et al Effective combinatorial immunotherapy for castration-resistant prostate cancer. Nature. (2017) 543:728. doi: 10.1038/nature21676

53. Kumar V, Cheng PY, Condamine T, Mony S, Languino LR, McCaffrey JC, et al. CD45 phosphatase inhibits STAT3 transcription factor activity in myeloid 
cells and promotes tumor-associated macrophage differentiation. Immunity. (2016) 44:303-15. doi: 10.1016/j.immuni.2016.01.014

54. Liu JF, Deng WW, Chen L, Li YC, Wu L, Ma SR, et al. Inhibition of JAK2/STAT3 reduces tumor-induced angiogenesis and myeloid-derived suppressor cells in head and neck cancer. Mol Carcinogene. (2018) 57:42939. doi: $10.1002 / \mathrm{mc} .22767$

55. McClure C, McPeak MB, Youssef D, Yao ZQ, McCall CE, El Gazzar M. Stat3 and C/EBP beta synergize to induce miR-21 and miR-181b expression during sepsis. Immunol Cell Biol. (2017) 95:42-55. doi: 10.1038/icb.2016.63

56. Wang ND, Finegold MJ, Bradley A, Ou CN, Abdelsayed SV, Wilde MD, et al. Impaired energy homeostasis in C/Ebp-alpha knockout mice. Science. (1995) 269:1108-12. doi: 10.1126/science.7652557

57. Zhang DE, Zhang P, Wang ND, Hetherington CJ, Darlington GJ, Tenen DG. Absence of granulocyte colony-stimulating factor signaling and neutrophil development in CCAAT enhancer binding protein alpha-deficient mice. Proc Natl Acad Sci USA. (1997) 94:569-74. doi: 10.1073/pnas.94.2.569

58. Hirai H, Zhang P, Dayaram T, Hetherington CJ, Mizuno S, Imanishi J, et al. C/EBP beta is required for 'emergency' granulopoiesis. Nat Immunol. (2006) 7:732-9. doi: 10.1038/ni1354

59. McPeak MB, Youssef D, Williams DA, Pritchett CL, Yao ZQ, McCall CE, et al. Frontline science: myeloid cell-specific deletion of Cebpb decreases sepsis-induced immunosuppression in mice. J Leukocyte Biol. (2017) 102:191200. doi: $10.1189 / \mathrm{jl}$. $4 \mathrm{HI} 1216-537 \mathrm{R}$

60. Marigo I, Bosio E, Solito S, Mesa C, Fernandez A, Dolcetti $\mathrm{L}$, et al. Tumor-induced tolerance and immune suppression depend on the C/EBP beta transcription factor. Immunity. (2010) 32:790-802. doi: 10.1016/j.immuni.2010.05.010

61. Gao YH, Shang WC, Zhang D, Zhang SW, Zhang XP, Zhang Y, et al. LncC/EBP beta modulates differentiation of MDSCs through downregulating IL4i1 With C/EBP beta LIP and WDR5. Frontiers in Immunology. (2019) 10:14. doi: 10.3389/fimmu.2019.01661

62. Gao YH, Sun W, Shang WC, Li YY, Zhang D, Wang TZ, et al. Lnc-C/EBP beta negatively regulates the suppressive function of myeloid-derived suppressor cells. Cancer Immunol Res. (2018) 6:1352-63. doi: 10.1158/2326-6066.CIR-18-0108

63. Mui ALF, Wakao H, Ofarrell AM, Harada N, Miyajima A. Interleukin3, granulocyte-macrophage colony-stimulating factor and interleukin-5 transduce signals through 2 Stat5 homologs. Embo J. (1995) 14:116675. doi: 10.1002/j.1460-2075.1995.tb07100.x

64. Zhan YF, Lieschke GJ, Grail D, Dunn AR, Cheers C. Essential roles for granulocyte-macrophage colony-stimulating factor (GM-CSF) and G-CSF in the sustained hematopoietic response of listeria monocytogenes - infected mice. Blood. (1998) 91:863-9. doi: 10.1182/blood.V91.3.863.863_863_869

65. Zeng Y, Broxmeyer HE, Staser K, Chitteti BR, Park SJ, Hahn S, et al. Pak2 regulates hematopoietic progenitor cell proliferation, survival, and differentiation. Stem Cells. (2015) 33:1630-41. doi: 10.1002/stem.1951

66. Zeng Y, Hahn S, Stokes J, Hoffman EA, Schmelz M, Proytcheva M, et al. Pak2 regulates myeloid-derived suppressor cell development in mice. Blood Adv. (2017) 1:1923-33. doi: 10.1182/bloodadvances.2017007435

67. Clevers H. Wnt/beta-catenin signaling in development and disease. Cell. (2006) 127:469-80. doi: 10.1016/j.cell.2006.10.018

68. White BD, Chien AJ, Dawson DW. Dysregulation of Wnt/beta-catenin signaling in gastrointestinal cancers. Gastroenterology. (2012) 142:21932. doi: 10.1053/j.gastro.2011.12.001

69. Famili F, Naber BAE, Vloemans S, de Haas EFE, Tiemessen MM, Staal FJT. Discrete roles of canonical and non-canonical Wnt signaling in hematopoiesis and lymphopoiesis. Cell Death Dis. (2015) 6:10. doi: 10.1038/cddis.2015.326

70. Skokowa J, Cario G, Uenalan M, Schambach A, Germeshausen M, Battmer $\mathrm{K}$, et al. LEF-1 is crucial for neutrophil granulocytopoiesis and its expression is severely reduced in congenital neutropenia. Nat Med. (2006) 12:11917. doi: $10.1038 / \mathrm{nm} 1474$

71. Poh TW, Bradley JM, Mukherjee P, Gendler SJ. Lack of Muc1-regulated betacatenin stability results in aberrant expansion of $\mathrm{CD} 11 \mathrm{~b}(+) \mathrm{Grl}(+)$ myeloidderived suppressor cells from the bone marrow. Cancer Res. (2009) 69:355462. doi: 10.1158/0008-5472.CAN-08-3806

72. Capietto AH, Kim S, Sanford DE, Linehan DC, Hikida M, Kumosaki T, et al. Down-regulation of PLC gamma 2-beta-catenin pathway promotes activation and expansion of myeloid-derived suppressor cells in cancer. J Experi Med. (2013) 210:2257-71. doi: 10.1084/jem.20130281

73. D'Amico L, Mahajan S, Capietto AH, Yang ZF, Zamani A, Ricci B, et al. Dickkopf-related protein 1 (Dkk1) regulates the accumulation and function of myeloid derived suppressor cells in cancer. J Experi Med. (2016) 213:82740. doi: $10.1084 /$ jem. 20150950

74. Qian YY, Yuan JP, Hu HL, Yang QF, Li JS, Zhang SQ, et al The CUL4B/AKT/beta-catenin axis restricts the accumulation of myeloid-derived suppressor cells to prohibit the establishment of a tumor-permissive microenvironment. Cancer Res. (2015) 75:5070-83. doi: 10.1158/0008-5472.CAN-15-0898

75. Li X, Xiang YW, Li FL, Yin CQ, Li B, Ke XS. WNT/beta-catenin signaling pathway regulating $\mathrm{T}$ cell-inflammation in the tumor microenvironment. Front Immunol. (2019) 10:12. doi: 10.3389/fimmu.2019.02293

76. Pai SG, Carneiro BA, Mota JM, Costa R, Leite CA, Barroso-Sousa R, et al. Wnt/beta-catenin pathway: modulating anticancer immune response. $J$ Hematol Oncol. (2017) 10:12. doi: 10.1186/s13045-017-0471-6

77. Iclozan C, Antonia S, Chiappori A, Chen DT, Gabrilovich D. Therapeutic regulation of myeloid-derived suppressor cells and immune response to cancer vaccine in patients with extensive stage small cell lung cancer. Cancer Immunol Immunother. (2013) 62:909-18. doi: 10.1007/s00262-01 3-1396-8

78. Wang ZB, Liu YQ, Zhang Y, Shang YM, Gao QL. MDSC-decreasing chemotherapy increases the efficacy of cytokine-induced killer cell immunotherapy in metastatic renal cell carcinoma and pancreatic cancer. Oncotarget. (2016) 7:4760-9. doi: 10.18632/oncotarget.6734

79. Fleming V, Hu XY, Weber R, Nagibin V, Groth C, Altevogt $\mathrm{P}$, et al. Targeting myeloid-derived suppressor cells to bypass tumor-induced immunosuppression. Front Immunol. (2018) 9:11. doi: 10.3389/fimmu.2018.00398

80. Liu GW, Bi YJ, Shen B, Yang H, Zhang Y, Wang X, et al. SIRT1 Limits the function and fate of myeloid-derived suppressor cells in tumors by orchestrating HIF-1 alpha-dependent glycolysis. Cancer Res. (2014) 74:72737. doi: 10.1158/0008-5472.CAN-13-2584

81. Liang HZ, Shen XL. LXR activation radiosensitizes non-small cell lung cancer by restricting myeloid-derived suppressor cells. Biochem Biophys Res Commun. (2020) 528:330-5. doi: 10.1016/j.bbrc.2020.04.137

82. Mita MM, Mita AC, Chmielowski B, Hamilton EP, Pant S, Waltzman RJ, et al. Pharmacodynamic and clinical activity of RGX-104, a firstin-class immunotherapy targeting the liver-X nuclear hormone receptor (LXR), in patients with refractory malignancies. J Clin Oncol. (2018) 36:2. doi: 10.1200/JCO.2018.36.15_suppl.3095

83. Sarha D, Brandt L, Felices M, Guldevall K, Lenvik T, Hinderlie P, et al. 161533 TriKE stimulates NK-cell function to overcome myeloid-derived suppressor cells in MDS. Blood Adv. (2018) 2:1459-69. doi: 10.1182/bloodadvances.2017012369

84. Stiff A, Trikha P, Wesolowski R, Kendra K, Hsu V, Uppati S, et al. Myeloidderived suppressor cells express bruton's tyrosine kinase and can be depleted in tumor-bearing hosts by ibrutinib treatment. Cancer Res. (2016) 76:212536. doi: 10.1158/0008-5472.CAN-15-1490

85. Vila-Leahey A, Oldford SA, Marignani PA, Wang J, Haidl ID, Marshall JS. Ranitidine modifies myeloid cell populations and inhibits breast tumor development and spread in mice. Oncoimmunology. (2016) 5:13. doi: 10.1080/2162402X.2016.1151591

86. Albeituni SH, Ding CL, Liu M, Hu XL, Luo FL, Kloecker G, et al. Yeast-derived particulate beta-glucan treatment subverts the suppression of myeloid-derived suppressor cells (MDSC) by inducing polymorphonuclear MDSC apoptosis and monocytic MDSC differentiation to APC in cancer. J Immunol. (2016) 196:2167-80. doi: 10.4049/jimmunol.1501853

87. Clavijo PE, Friedman J, Robbins Y, Moore EC, Smith E, Zauderer M, et al. Semaphorin $4 \mathrm{D}$ inhibition improves response to immune-checkpoint blockade via attenuation of MDSC recruitment and function. Cancer Immunol Res. (2019) 7:282-91. doi: 10.1158/2326-6066.CIR-18-0156

88. Younis RH, Han KL, Webb TJ. Human head and neck squamous cell carcinoma-associated semaphorin 4D induces expansion of myeloid-derived suppressor cells. J Immunol. (2016) 196:141929. doi: $10.4049 /$ jimmunol.1501293 
89. Tobin RP, Jordan KR, Robinson WA, Davis D, Borges VF, Gonzalez R, et al. Targeting myeloid-derived suppressor cells using all-trans retinoic acid in melanoma patients treated with ipilimumab. Int Immunopharmacol. (2018) 63:282-91. doi: 10.1016/j.intimp.2018.08.007

90. Mackert JR, Qu P, Min YF, Johnson PF, Yang L, Lin PC. Dual negative roles of $\mathrm{C} / \mathrm{EBP}$ alpha in the expansion and pro-tumor functions of MDSCs. Sci Rep. (2017) 7:11. doi: 10.1038/s41598-017-12968-2

91. Plunkett W, Huang P, Searcy CE, Gandhi V. Gemcitabine: Preclinical pharmacology and mechanisms of action. Semin Oncol. (1996) 23:3-15.

92. Gargett T, Christo SN, Hercus TR, Abbas N, Singhal N, Lopez AF, et al. GM-CSF signalling blockade and chemotherapeutic agents act in concert to inhibit the function of myeloid-derived suppressor cells in vitro. Clin Transl Immunol. (2016) 5:12. doi: 10.1038/cti.2016.80

93. Le HK, Graham L, Cha E, Morales JK, Manjili MH, Bear HD. Gemcitabine directly inhibits myeloid derived suppressor cells in BALB/c mice bearing 4T1 mammary carcinoma and augments expansion of $\mathrm{T}$ cells from tumor-bearing mice. Int Immunopharmacol. (2009) 9:9009. doi: 10.1016/j.intimp.2009.03.015

94. Kusmartsev S, Su Z, Heiser A, Dannull J, Eruslanov E, Kubler H, et al. Reversal of myeloid cell - mediated immunosuppression in patients with metastatic renal cell carcinoma. Clin Cancer Res. (2008) 14:82708. doi: 10.1158/1078-0432.CCR-08-0165

95. Otvos B, Silver DJ, Mulkearns-Hubert EE, Alvarado AG, Turaga SM, Sorensen MD, et al. Cancer stem cell-secreted macrophage migration inhibitory factor stimulates myeloid derived suppressor cell function and facilitates glioblastoma immune evasion. Stem Cells. (2016) 34:202639. doi: 10.1002/stem.2393

96. Scheller M, Schonheit J, Zimmermann K, Leser U, Rosenbauer F, Leutz A. Cross talk between Wnt/beta-catenin and Irf8 in leukemia progression and drug resistance. J Experi Med. (2013) 210:2239-56. doi: 10.1084/jem.20130706

Conflict of Interest: The authors declare that the research was conducted in the absence of any commercial or financial relationships that could be construed as a potential conflict of interest.

Copyright (C) 2020 Kramer and Abrams. This is an open-access article distributed under the terms of the Creative Commons Attribution License (CC BY). The use, distribution or reproduction in other forums is permitted, provided the original author(s) and the copyright owner(s) are credited and that the original publication in this journal is cited, in accordance with accepted academic practice. No use, distribution or reproduction is permitted which does not comply with these terms. 